\title{
Research on the Relationship between Occupational Recognition and Employment Quality of Medical Students under the Pattern of Innovative Talents \\ Huanquan Shen ${ }^{1}$, Qiang $\mathrm{Li}^{2^{*}}$ and Min Chen ${ }^{3}$ \\ Qiqihar Medical University, Heilongjiang 161006 \\ ${ }^{1}$ Basic Medical University ${ }^{2} *$ School of Nursing ${ }^{3}$ Admissions and employment office an99004@126.com
}

\begin{abstract}
Keywords: Pattern of innovative talents; Medical Students; Professional identity; Quality of employment
\end{abstract}

\begin{abstract}
In recent years, the country has put forward the pattern for education and cultivation innovative talents. As the core base for implementing the strategy of strengthening the nation by talents, the application of the pattern for education and cultivation innovative talents to the students in colleges and universities becomes very important to the students themselves, even the whole nation. Under the mode of cultivating innovative talents, it is necessary for university and college students to cultivate their own professional identity, and such training will directly affect the employment quality of university and college students. This article take researches on the relationship between professional identity and employment quality under the pattern for education and cultivation innovative talents, based on the case study of medical students . Through the analysis of the employment quality of medical students in colleges and universities, it is found that there is a close relationship between the decline of employment quality and the medical students' professional identity. This article profoundly studies the intrinsic relationship between the two and the factors affecting professional identity. Meanwhile, some suggestions are proposed on how to promote the professional identity and improve the employment quality from the respects of schools, societies, as well as medical students.
\end{abstract}

\section{Introduction}

In March 2016, the CPC Central Committee issued the "Opinions on Deepening the Reform of the System and Mechanisms for Talents Development" which mentioned that as improving the support system for talent cultivation requires the pattern for education and cultivation innovative talents, much attention should be paid to cultivating students' innovative awareness and innovative ability. The state has always attached great importance to the training of creative talents in universities and colleges and formulated and implemented the strategy of invigorating China through science and education and strengthening the nation by innovative talents. All colleges and universities have formulated corresponding training models for innovative personnel in light of their own actual conditions. The cultivation of innovative talents can not be separated from the cultivation of professional identity for college students, and such training will directly affect the employment quality of college students.

This article take researches on the relationship between professional identity and employment quality under the pattern for education and cultivation innovative talents, based on the case study of medical students

As a profession that has been long respected and highly valued, medical workers should have been greatly appreciated by society and college students, especially for those students who have already majored in medicine and received professional knowledge and training. But it seems that the fact is not what we expected. Medical workers are persons who race with time to save people's lives and try their all best to keep people away from the illness and diseases. It is a profession can only be accomplished by the medical students, who are equipped with sufficient expertise and skills. As a medical student, being a medical worker seems his/her first and most reasonable choice. However, the "China Youth Daily", one of the most famous Chinese newspapers once reported that 
"In China, nearly 600,000 medical graduates left school every single year, of which 500,000 graduates chose to find another way out instead of being a medical worker for reasons, and only about 100,000 graduates finally made it, realizing their dreams of wearing the "white coats" . The education of medical colleges and universities in China has entered into an odd mode of "extensively cultivated but low outputs" [1]. This fact has reflected a sharp decline in the medical graduates employment, both in numbers and qualities.

From the angle of current employers, the reason for the decline in the quality of employment for the medical graduates shall attribute to the higher and higher requirements for the fresh medical graduates. When doing interviews, the employers seem to care much more than expertise, skills and other professional qualities. Judgement shall be given on the interviewees to find out whether they have the professional identity, how long can they keep their interests on the job, as well as the loyalty. From a student's point of view, there are some measures can be done to improve the employment quality, such as cultivating and developing professional identity, making a clear career orientation, formulating a career planning and taking sufficient preparations so that they can calmly face the sever employment situation and shorten the adapting period of being a staff from a student. Therefore, in order to further improve the quality of employment of medical students, we must fully understand the relationship between the cultivation of professional identity and the quality of employment of medical students and take this into account.

In addition, professional identity also affects the medical students in terms of job satisfaction, job burnout, even in their future career life. It plays an essential role in the career development. The negative opinion of medical students on professional identity (none or low) shall affect their tendency to becoming medicine workers and even make them suspect their choices after they chose to undertake a medical job. Under the current severe employment situation, the employment-oriented approach is indeed the right way for college and universities to choose. However, at the same time, more attention should be paid to the employment quality of medical students to ensure the continuous delivery of high-quality talents to our country[2]. Professional identity is a concept of psychology, which is referred to the fact that the individual's view of the career goals, social values and other factors conforms with the social evaluation and expectation on his occupation, in another word is that the individual totally agree or accept the opinions, expectations on the occupation he/she is engaged in from others or groups[3]. The researches on professional identification of medical students are rarely to be found at home or abroad. In China, the study undergoing on the occupational identification of medical students is much less than we thought. Only the researches on the similar kind of concepts can be referred to, such as professional ethics, professional accomplishments, professionalism and so on. What worse is that even the research on the similar kind of concepts still stays at the level of the theoretical research and experience summary, lack of empirical study. And so it is for the research on the theme of professional identity, which is also a newly explored study area in the last decade. These research, and the professional identity studies on nursing students, normal students and teachers groups were much familiar to us [4.5]. A nursing student's professional identity questionnaire, which was formulated by Hao Yufang and other researchers, defines the professional identity as three dimensions: career self-recognition, career self-experience, career self-control. A career self-recognition includes career acceptance, career beliefs, career orientation, social comparing awareness and social skills; a career self-experience includes career feelings, self-esteem, happiness and feeling for career self-efficacy; a career self-control includes self-motivation, self-reflection and self-planning [6]. Li Yan, a domestic scholar, assumes that to cultivate the professional identity of medical students is actually to cultivate their senses of professional responsibility, professional honor and professional dignity so that they will come out a highly respected professional sanctity, a sense of mission and a deep love for medicine and take the medicine as "Renshu", in Chinese which means a science or technology full of cares and mercy with purpose of relieving the patient's pain. With this kind of awareness, the medical students are capable to study medical knowledge [7.8] much more self-motivated. Simone. K, a foreign scholar remarked that the professional identity should be taken as a phenomenon including multi-dimensions, which is the structural dimensions, 
social dimensions and individual psychological dimensions [9].

\section{Research and analysis}

Innovative talents training pattern requires the analysis and problem solving process not to be rigidly adhered to the routine and encourages to seek for answers from changeable and multiple angles. Based on the research background of domestic and foreign literature on professional identification of medical students, combined with the questionnaire and analysis on the influence of professional identification on the quality of employment of medical students from three medical colleges and universities, this article concludes that there is a close relationship between the professional identification and the employment quality of medical students under the pattern of innovative talents. In this article, constructive suggestions are put forward after a profound analysis on the deep-seated reasons and factors that affect the relations of the professional identification and the employment quality.

Qiao Ruihong, a researcher from Henan Medical College, carried out her investigations on the medical students from three different higher vocational medical schools in terms of questionnaires and interviews. She selected three higher vocational medical schools and distributed 380 questionnaires. It was found that in the future employment, $82.03 \%$ of the objects of investigation preferred to choose cities as the working location, followed by the county, while no considerations are given for the township and rural area. The reason why majority of vocational medical students prefer to work in the cities is that the comparably well-built urban employment mechanism, which can better meet their requirements on employment environment, salaries and welfare, development and further studies, etc. The main reasons why vocational medical students feel less professional identity don't attribute to disagreement to the medicine major. Their disagreement with the employment area and their unwillingness to work in grass-roots units, and township(rural area) are the factors responsible for the less professional identity [10]. Chen Chiwei and Lin Jianfeng, researcher from the First Clinical College of Wenzhou Medical College, conducted questionnaires survey on the 400 fresh graduates of the college mentioned above in 2011. According to the completed questionnaires, for the question of "having a strong sense of identity for the doctor's profession," none of them chose the item of "very agreeable". It reflected a general appearance of missing "pride" and lower professional identity. When being asked "I still choose the major in medicine science if I have another chance," only 3.9\% of investigation objects chose the item of "strongly agreed" and only $0.6 \%$ said "I wish I could pursue the medical career until retirement". These results indicated that their beliefs, to be proud of being a medical worker, face a severe test. In their survey of question"opinions on the current practice environment for doctors," $47.4 \%$ chose the item of "normal", which revealed their dissatisfaction with the doctor's practice environment and not being optimistic about the future of the profession [11]. SU Jiahua, a researcher from School of Education of Suzhou University, compiled questionnaires for 410 medicine science students covering from freshman to junior in three dimensions: career goals, career exploration, and career achievement respectively representing the determination for individual to select the doctor as a lifelong occupation, the promotion for individual to better understand the occupation through active exchange and self-reflection and the clearly awareness for the individual to figure out the usefulness of occupation for their own development. It was found that the professional identity of medical students as a whole only reached the upper middle level [12].

\section{The relationship between professional identity and employment quality}

Through the above practical investigation, it is revealed that in present medical colleges and universities, situations of low quality of employment and professional identity among medical students do generally exist. Most of the students, even for the excellent young students, are motivated to go to medical schools based on the thinking of "doctor is a stable career with professional knowledge and skills, which probably leads the easier and better life". As they take medical studies as a means to earn a living in the future rather than a respectful and meaningful 
career, their sense of professional responsibility and honor is relatively weak. The lack of professional identity will greatly affect the employment quality of medical graduates from colleges and universities. [7.13.14].

From the point of view of cultivating creative college students, it shows that the thinking pattern of medical students is still relatively fixed, and the cultivation of innovative thinking is far from enough. It can be analyzed from the following aspects.

\section{The employment situation is grim}

In the late 1990s, Chinese universities and colleges started a large-scaled enrollment expansion. According to the "2006 China Health Human Resources Report" released by the Statistics Information Center of the Ministry of Health, the number of fresh graduates in 2005 was about 520,000 . In contrast to this, in the same year, the number of health and medical graduates hired by the health authorities was only 120,000 [15]. Although presently medical graduates had been oversupplied, the enrollment expansion pace of medical universities and colleges has not stopped. The employment difficulties of medical graduates are still gradually aggravated. The severe employment situation for them has drawn great attention from all walks of life. In addition, most medical graduates want to stay in a large hospital bounding in good conditions. However, the large and medium-sized hospitals have higher requirements for qualified personnel, which led many medical undergraduates to choose making preparations for postgraduate examinations. However, some employed medical students were unable to adapt to the high-intensity hospital work and switched to another field [9].

\section{The medical working environment is severe}

Many medical students have dreamed to become a good doctor by virtue of their professionalism and hard working, expecting the value of doctors can be recognized by people and their paying can be rewarded by the social. However, under the current complicated medical environment, the medical system reform still has a long way to go and the good relations between doctors and patients also need a long time of practicing. Under the current medical system, the medical environment faced by doctors is very complicated. On the one hand, the allocation of health resources in China is far from reasonable. The medical facilities equipped in hospitals at the county level and below are mostly inadequate, and so it is for the hospital management systems and operating mechanisms. Furthermore, the financial support from the competent authorities to these hospitals was very limited, which has greatly affected the improvement of the medical environment. On the other hand, China has suffered from the problem of "difficult to see the doctor and costly to be cured" for a long time, which has not been effectively improved. While the patients are paying for the high medical costs, there is an inevitable compensation psychology forming in their minds. They want the effective treatment equivalent to the money they have paid. Once the treatment fails or the treatment is not such satisfactory, patients and their families would be very frustrated and emotional. They would tend to contribute the failure to the doctors and hospitals, which can easily lead medical disputes. The public are usually lack of medical knowledge and holding high expectations but lower trust in doctors, resulting in many conflicts between doctors and patients.

\section{Professional training of medical students was not well-matched with the society needs}

At first, China has the most diverse and complex medical education and training model on medical students training all over the world. However, according to the successful experiences of other countries, the basic consistency of the academic system can make the training orientation clearer, as well as the training methods. Under the total training objectives, the specific training objectives for schools at different levels can be changed according to the situation, thus diversifying the talents training. Back to China, there are many levels, complex structures, chaotic educational systems in the medical education, which not only resulted in the non-uniform specification of personnel 
training, but also the difficulty in formulating accurate and targeted training objectives and evaluation criteria, resulting in the inaccurate distinction of qualified personnel and difficulty in guaranteed its quality. Second, the medical major curriculum is over-designed with too much detailed subject. Compared with the American students who can apply for a medical school only after graduating with a bachelor's degree from a university for four years, medical students in our country are directly promoted from high schools. The academic system is only four or five years, while the majors are as many as 50 or so . So narrow but detailed major settings likely lead to non-sufficient foundation training. The majors curriculum settings and personnel training are disconnected with social actual needs. The structural contradictions between medical education and social medical practice demands are very prominent [14].

\section{Potential employment choices are less}

When seeking and choosing employment, medical students put so much energy to strive for position in big hospitals or hospitals located in big cities, instead of going to vast rural areas and western areas where medical workers are extremely scarce, to change their backward medical and health situations. Guiding medical students to rural areas after graduation to change their lack of medical treatment and medicine materials is theoretically correct, but this is far from enough to change this situation only by virtue of the moral appeal and awareness. As a result, the employment competition for medical students in big cities is becoming more and more intense, while the resources in poor and backward areas was still scarce. From a practical point of view, many graduates are compelled to enter grassroots hospitals. However, there are many problems long existing in the grassroots hospitals of many areas, such as inadequate staffing structure or unreasonable structures, less potential for career development and low incomes. These problems make many medical students become hesitated when deciding whether to go to work in grassroots hospitals, as these units are incapable to provide a good development for medical students and there are less factors to inspire medical students choose to work at the grass-roots level [16].

\section{Suggestions and coping strategies}

The above paragraph we analyzed the relationship between the professional identity and the quality of the employment of medical students under the pattern of innovative talents, as well as the deep reasons that influence the quality of the medical students' employment and the professional recognition of the medical students. It is significant for the medical students to be fostered with the sense of professional responsibility, professional honor and professional dignity under the pattern of innovative talents in the realm of "medicine is based on virtue and the virtue makes a doctor", which is an old Chinese saying for the medical workers. The following are recommendations and coping strategies regarding to cultivate medical students occupational identity and enhancing the quality of employment of medical students [17.18].

From an objective perspective, the successful medical education needs the attention of the community and schools and their cultivation under the pattern of innovative talents.

\section{The school should strengthen the education of medical students on professional identity}

People in medical field always emphasized that "medical practitioners with love and mercy" which can be used as a social virtue, but also the professional ethics of the medical profession. Based on this moral foundation, we should further clarify the cultivation of "patient-centered" medical professional ethics as the most important aspect of professional identity education for medical students. About this education, we can learn from pattern in the United States for their creative medical students education. In the United States, medical freshmen need to reach out to patients in the first week of their schooling to understand the "pains" that patients are suffering from. Through close observation of the patient from the very beginning before they started their medical study, the students can deeply understand the patient's pain and anxiety, as well as the happiness and gratitude 
after they being healed, to cultivate the students' benevolence toward the patient. In the process of teaching, the medical students can also simulate patients. Through role playing, the medical students can learn empathy, which means to think in the patient's point of view, to understand patient's panic against disease and desire for life, and the hope to be cared about by medical workers, to deepen this sense of "love and mercy" of the practitioners. Therefore, from the first day when freshmen enter school, this professional ethics education should be carried out in an all-round and long-term way. The primary task faced by the medical school educators is to help medical students to develop a sense of professional identity, so that medical students would have a lofty professional sanctity, sense of mission, a deeply affection for medicine and respect the medicine as "Renshu". This is the very motivation for medical students to study all the professional courses and practicing skills.

\section{Create a good public opinion environment and establish a harmonious doctor-patient relationship}

Creating a harmonious and good medical environment can not be achieved just by doctors' efforts and patient understanding. It also requires strong and constant support from all walks of life with the thinking of cultivating innovative talents. First of all, at a national level, measures should adopt to repair and enhance the patient-doctor relations, such as domestic health care reform in different levels and areas should be carried out consistently, the social medical security system should be continuously improved, and the medical input should gradually increase, and the relevant laws and regulations should be adjusted to protect the rights and benefits for both patients and medical workers. At the public opinions level, the media, especially the influential press and internet websites, should try every means to promote the communication between doctors and patients so as to solve problems based on the objective and peaceful exchanges between doctors and patients. Only in this way, doctors can leave out the heavy mental burdens to provide patients with timely and effective relief. Through these measures, we can create a harmonious atmosphere for medical treatment, a good medical practice environment for medical students and increased their positive emotions and expectations for future careers, to be an honorable medical worker[19].

\section{Formulate more preferential policies to encourage medical students to go to work in hospital at grassroots level}

National or local governments may formulate relevant creative preferential policies according to their own actual conditions to encourage medical graduates to work in community health centers or rural health units. This action not only helps to improve the conditions and level of primary medical care, but also helps to reduce the waste of resources caused by over-assembly of medical human resources in major cities and tertiary hospitals, thus alleviating the employment pressure for medical students [13].

From the medical students themselves, the following two aspects need to pay attention to in creative point of view.

\section{Intensive and thorough study on the medical profession}

Innovation is inseparable from the foundation, and professional identity can not work without a solid school education. There are Chinese old words saying: "The most essential thing for medicine study is proficiency. An unqualified doctor may do harm to people", "The medicine is a technique to save people's lives. Doctors without perfect expertise are incapable to cure people." As it is concerned about the patient's life and safety, the requirements on medical worker's professional ability are particularly strict. When studying at school, medical students should have a rigorous academic attitude and the spirit of seeking excellence, which are also an essential part of medical professional identity education. Besides benevolence, medical student should solidly maser professional knowledge and superb medical practice skills to realize the professional identity. In 
learning process, it is necessary for medical students to acquire comprehensive knowledge at the same time deeply understand it. Many efforts should be taken to inspire the curiosity of medical students, mobilize the enthusiasm of medical students to lay a solid theoretical foundation for them to become qualified doctors in the future [7].

\section{To enhance the medical students' sense of mission as medical workers and awareness to work in hospitals at the grassroots}

Medical students should change their opinions on employment and increase their sense of mission as a medical worker. They should clearly understand that the state is gradually increasing the investment and stepping the reforming pace in the primary-leveled hospitals so that primary-leveled hospitals can deal with more medical tasks. Numerous primary hospitals are currently short of high-quality medical professionals, which providing vast space for them to realize their professional ambitions. Excellent medical professionals should not only possess superb professional skills, but also equipped with high ethical standards and perfect personality qualities. They understand the difficulty in medical conditions at grassroots hospitals and the support from the state. They have clear personal career goals to achieve by reasonable planning. They will make full use of what they have learnt at school to achieve personal aspirations [20].

\section{Conclusions}

Under the pattern of innovative talents, to cultivate the professional identity is an important part of innovation cultivation for college students and it will further enhance the employment quality of them. In return, the improvement of the quality of employment will increase their professional identity, which would be a truly innovative education and cultivation pattern.

\section{Acknowledgment}

Address: Qiqihar Medical University, Bukui North Street, Jianhua District, Qiqihar City, Heilongjiang Province

Fund Project: Heilongjiang Educational Science "Thirteenth-five Plan" 2017 Annual Key Project (No.GBB1317140)

\section{References}

[1] Sun Haitao. Talking about the Cultivation and Training System of Innovative Talents in Colleges and Universities [J]. China Training 2017 (06): 54.

[2] $\mathrm{Hu}$ Daosheng. Analysis of Occupational Identity Status and Influencing Factors of Vocational College Students [J]. Tianjin University 2015 (20)

[3] Zhang Min. Study Review of Professional Identity and Occupational Development of Foreign Teachers [J]. Comparative Education Research, 2006 (2): 77-81

[4] Zhang Lili. Study of Occupational Identity Status and Influencing Factors of Medical students [D]. 2010. East China Normal University, Master's thesis 6-10,

[5] Wu Qi, Zhou Jun, Huang Xiangjin, etc. Analysis of Occupational Identity Status of Medical Students[J]. Chinese General Practice, 2017.15 (09) 1542-1545

[6] Hao Yufang, Liu Ling, Liu Xiaohong. Study of Occupational Identity of Nursing Students [J]. Psychological Science, 2008 (5) 32

[7] Li Yan. Method Study of Strengthening Occupational Identity Education of Medical Students[J], Medicine and Society, 2005 (3): 63-64

[8] Fang Yanjun, Zhou Jun, Huang Min, etc., Analysis of Occupational Quality Development from the Occupational Identity Status of Medical students [J], Health Vocational Education 2017, (05) $11-12$

[9] Simone.K.Work. Identities of nurses: Between caring and efficiency demands. Career 
Development International, (2004). 9 (3), 274-304.

[10] Qiao Ruihong, Analysis of Occupational Identity Issue of Higher Vocational Medical Students [J]. Journal of Henan Medical College for Staff and Workers, 2014 (01): 112: -116.

[11] Chen Chi-Wei, Lin Jian-feng. Research on occupational identity survey of medical students [J]. Wenzhou Medical College First Clinical College (2013) 03-119-120.

[12] Mao Jia Huan, Study of Occupational Identity status of Colleague Students Majored in Medicine [J]. Application Research (Social Psychology) .2015, 30 (1) 45-50

[13] JI Xiaohong, Wang Wenjun, Hou Shan, etc. Investigation and Analysis of Occupational Identity of Medical Students [J]. Journal of Jining Medical College, 2015,38 (1): 71-74

[14] Gao Yunshan, Zhang Lina, Ma Xiaoling. Influence of Doctor - Patient Relationship on Occupational Identity of Medical Students and Its Countermeasures. Yinshan Academic Journal (Natural Science Edition) 2016 (04) 29-32

[15] Wu Yin Xin. Status Quo and the Development of Chinese and Foreign Medical Educational System [D]. Fujian: Fujian Medical University, 2009

[16] Wang Ying, Song Yaoxin. Urgency and Tactics Analysis of Career Planning Education of Medical Students [J]. Heilongjiang Higher Education Research, 2015 (8): 85-87.

[17] Li Hongying. Higher Medical Education in the Era of Popular Education [J]. Employment of China University Students: 2003., 10: 58

[18] Huang Xianhong, Lin Lujing, Wang Xiahe, etc. Analysis of Grassroot Employment Intention and Influencing Factors of Medical Students [J]. China Health Policy Research 2014 (08) 46-50

[19] Wang Juqian, Gu Wei, Lu Yi Hua. Analysis of The Influence on The Occupational Choice and Employment of Medical Students by The Doctor-Patient Relationship Status Quo[J]. Modern Preventive Medicine 2015 (16) 2956-2958

[20] Fu Yi. Analysis on employment status and its related influencing factors for graduates from Fudan University Zhongshan Hospital Zhongshan Medical College[D]. Fudan University 2010 37 